\title{
Effects of Paretic Single Limb Exercise on Vascular Characteristics Changing of Bilateral Femoral Arteries on Sub Acute Stroke Patients
}

\author{
Wiwiet Irmayanti, Novitri, Dian M Sari \\ Department of Physical Medicine and Rehabilitation \\ Faculty of Medicine Padjadjaran University- Hasan Sadikin General Hospital \\ Jl. Prof. Eyckman No. 38 Bandung 40161 Indonesia \\ Email :wietirmayanti@gmail.com
}

\begin{abstract}
After a stroke, individuals have weakness and decrease mobility of the hemiparetic side, which demands less muscle oxygen consumption; thus, blood flow decrease. It interferes the hemodynamic system include vascular characteristics. The single limb (quadriceps) exercise intervention was aerobic training that focused only on the hemiparetic limb. The aims of this study was to determine the effects of the single limb exercise on vascular characteristics of both side femoral arteries using pre and post-interventional study. Twelve participants in subacute phase of stroke, performed endurance exercise using $N-K$ table on the hemiparetic leg three times a week for eightweeks. The diameter, peak systolic velocity (PSV), total average maximal velocity (TA Max) of both side femoral arteries were measured. We found that the changing of vascular characteristics outcomes on both side femoral arteries were not statistically significant increased. Others factors that may impede vascular characteristics in both femoral arteries were blood viscosity, aging process and periods of exercise.
\end{abstract}

Keywords: femoral arteries, paretic, stroke, vascular characteristics 


\title{
Pengaruh Latihan Ketahanan Otot Kuadrisep Sisi Paretik terhadap Perubahan Karakteristik Vaskular Arteri Femoralis pada Stroke fase Subakut
}

\author{
Wiwiet Irmayanti, Novitri, Dian M Sari \\ Departemen Kardiologi dan Kedokteran Vaskuler, Fakultas Kedokteran Universitas \\ Padjadjaran - Rumah Sakit Umum Hasan Sadikin Bandung \\ Jl. Prof. Eyckman No.38 Bandung 40161 Indonesia \\ Email : wietirmayanti@gmail.com
}

\begin{abstract}
Abstrak
Stroke menimbulkan gejala kelemahan otot sisi hemiparetik. Pada sisi hemiparetik kebutuhan oksigen dan suplai aliran darah berkurang. Stroke juga memengaruhi kondisi hemodinamik termasuk karakteristik vaskular pada pembuluh darah. Latihan ketahanan kuadrisep sisi paretik adalah latihan yang berfokus pada satu tungkai saja. Tujuan penelitian ini adalah untuk mengetahui efek latihan ketahanan kuadrisep sisi paretik terhadap perbaikan vaskular arteri femoralis pada sisi paretik maupun nonparetik. Penelitian ini menggunakan satu kelompok subjek dengan perbandingan sebelum dan sesudah perlakuan. Dua belas subjek penelitian penderita stroke subakut mengikuti latihan ketahanan kuadrisep sisi paretik sebanyak tiga kali seminggu selama delapan minggu menggunakan $\mathrm{N}-\mathrm{K}$ table. Variabel yang diukur menggunakan USG Dopler adalah diameter, kecepatan puncak sistolik (PSV) dan kecepatan maksimal rata-rata (TA Max) arteri femoralis sisi paretik dan nonparetik. Hasil penelitian menunjukkan latihan ketahanan otot kuadrisep sisi paretik meningkat namun tidak berpengaruh secara signifikan terhadap perubahan karakteristik vaskular pada sisi paretik maupun nonparetik. Faktor viskositas darah, proses penuaan dan periode latihan mungkin mempengaruhi adaptasi vaskular arteri femoralis kedua tungkai tersebut.
\end{abstract}

Kata kunci: arteri femoralis, paretik, karakteristik vaskular, stroke 


\section{Pendahuluan}

Stroke adalah manifestasi klinis dari gangguan fungsi otak baik fokal maupun menyeluruh yang berlangsung cepat, lebih dari dua puluh empat jam atau sampai menyebabkan kematian tanpa penyebab lain selain gangguan vaskular. ${ }^{1}$ Data Riset Kementrian Kesehatan tahun 2013 menunjukkan, jumlah penderita stroke berdasarkan diagnosis tenaga kesehatan diperkirakan mencapai 1.236 .825 orang ( $7 \%$ ) dari seluruh penduduk Indonesia. Provinsi Jawa Barat memilikiestimasijumlahpenderita stroke terbanyak, berdasarkan diagnosis tenaga kesehatan sebanyak $7 \%$ dan berdasarkan diagnosis gejala sebanyak 16,6\%. Angka disabilitas yang diakibatkan meliputi 1,6\% menetap dan 4,3\% mengalami perburukan. ${ }^{2,3}$

Stroke menyebabkan perubahan struktural, metabolik, fungsional dan vaskular pada jaringan sisi paretik. Perubahan struktural pada jaringan otot berupa penurunan massa otot, perubahan penampang melintang, peningkatan lemak intramuskular dan perubahan komposisi tipe serabut otot. Proporsi serabut otot tipe II yang bersifat glikolitik dan memiliki sedikit kapiler akan meningkat pada sisi paretik. Perubahan karakteristik vaskular dan disfungsi endotel terjadi seiring perubahan structural jaringan di sisi paretik. Sistem vascular sisi paretic akan mengalami perubahan sehubungan dengan pengurangan kebutuhan metabolik, perubahan masa otot dan peranan kontrol otonom. ${ }^{4,5.6}$

Beberapa penelitian menunjukkan bahwa intervensi latihan aerobic terbukti memengaruhi perubahan vaskular pada pasien-pasien dengan obesitas, diabetes mellitus tipe 2 , trauma medula spinalis, penyakit jantung koroner dan pada populasi usia lanjut. Perubahan vaskular yang terjadi pasca-intervensi latihan secara regular akan meningkatkan aliran darah yang dimediasi melalui efek vasodilatasi dan remodeling pembuluh darah. ${ }^{5,7}$

Proses pemulihan stroke paling progresif terjadi dalam tiga bulan pertama. Proses ini terus berlangsung hingga enam bulan dan akan melambat setelahnya. Pemulihan fungsional yang optimal perlu dilakukan dengan pemberian terapi dan tatalaksana rehabilitasi pada fase ini. Latihan merupakan pilihan utama dalam tatalaksana rehabilitasi stroke. Efek latihan yang terprogram dan berkelanjutan dapat meningkatkan adaptasi hemodinamik yang berdampak pada perbaikan vaskular dan fungsi endotel lokal maupun sistemik ${ }^{8,9,10,11}$

Intervensi latihan pada penderita pasca stroke kebanyakan berfokus pada aktivitas latihan bilateral (sisi paretik dan nonparetik) seperti treadmill, latihan berjalan atau latihan bersepeda. Beberapa penelitian membuktikan pada latihan bilateral terdapat penurunan performa kerja dari sisi paretic dibandingkan sisi nonparetik. Hal tersebut mendasari diperlukannya suatu identifikasi efek dari strategi latihan yang akan berfokus secara primer pada sisi paretik, sehingga menghasilkan performa yang lebih maksimal untuk sisi paretik. ${ }^{5,6,7}$ 
Tungkai bawah berkontribusi lebih dari $40 \%$ porsi kapasitas aerobik. Intervensi ekstremitas bawah satu sisi dapat menstimulasi konsep forced-use pada tungkai paretik, meningkatkan ambilan oksigen dan aliran darah. Latihan satu tungkai berpotensi mencegah penurunan performa kerja oleh tungkai hemiparetik selama latihan bilateral. ${ }^{5,67,12,13}$

Penelitian ini bertujuan mengetahui manfaat latihan ketahanan otot kuadrisep sisi paretik yang diberikan pada pasien stroke fase subakut terhadap perubahan karakteristik vascular berupa perubahan diameter, kecepatan puncak sistolik (Peak Systolic Velocity $=$ PSV) dan rata-rata kecepatan maksimal (Time Average Maximal Velocity = TA Max) pada arteri femoralis sisi paretik dan nonparetik ${ }^{5,6,9,10,11}$

\section{Metode}

Rancangan penelitian ini merupakan merupakan studi quasi eksperimental perbandingan sebelum dan sesudah perlakuan yaitu pada awal dan akhir perlakuan. ${ }^{14}$ Pengambilan data dilakukan menggunakan metoda total sampling selama periode Juli 2017 sampai dengan Januari 2018 di Departemen Ilmu Kedokteran Fisik dan Rehabilitasi Universitas Padjadjaran - RSUP Dr. Hasan Sadikin Bandung. Kriteria penerimaan subjek penelitian meliputi pasien yang didiagnosis sebagai hemiparesis karena stroke, dalam fase subakut (2 minggu - 4 bulan pasca serangan stroke pertama), berusia antara 40-59 tahun, mampu transfer dari posisi duduk ke berdiri, mampu mengekstensikan dan memfleksikan lutut dengan lingkup gerak sendi penuh, kekuatan otot fleksor dan ekstensor lutut minimal 3, spastisitas maksimal 1 (Modified Asworth Scale), tidak ada gangguan propriosepsi dan sensoris berat, mampu menjalankan instruksi lisan, serta bersedia menjadi subjek penelitian. Kriteria penolakan subjek penelitian meliputi stroke kardioemboli, terdapat gangguan vaskular atau masalah muskulo skeletal anggota gerak bawah, terdapat riwayat penggunaan obat isosorbid dinitrat. Kriteria pengeluaran subjek penelitian meliputi cedera selama periode latihan atau tidak mengikuti latihan 2 kali berturut-turut.

Pengukuran nilai diameter pembuluh darah, PSV dan TA Max arteri femoralis sisi paretik dan nonparetik menggunakan alat ultrasound Dopplermerk GE Voluson $S 8$ di laboratorium Pramita Cabang Padjadjaran Bandung. Pemeriksaan dilakukan oleh satu orang dokter ahli Radiologi yang kompeten dalam pemeriksaaan USG Doppler.

Intervensi latihan diberikan 3 kali perminggu selama 8 minggu. Latihan menggunakan $\mathrm{N}$-K table (gambar 1). Intensitas beban 40\% dari $1 \mathrm{RM}$ pada tingkai sisi paretik, dengan repetisi 25 kali dan dilakukan sebanyak 3 set. Waktu istirahat antar set adalah 2 menit. Pengukuran ulang variabel-variabel output penelitian, minimal 24 jam setelah latihan. 


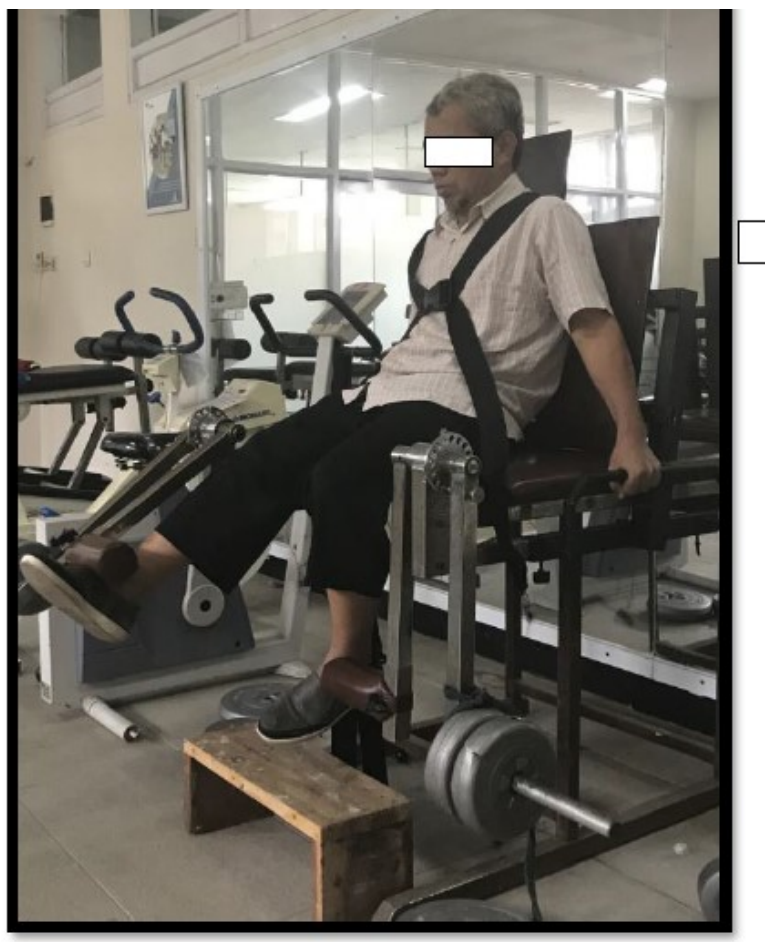

\section{Gambar 1 Latihan Ketahanan Tungkai Sisi Paretik dengan $\mathrm{N}-\mathrm{K}$ table}

Analisis secara deskriptif digunakan untuk menggambarkan karakteristik subjek penelitian yang menjadi sampel penelitian. Analisis statistik untuk data numerik (diameter pembuluh darah, PSV dan TA Max arteri femoralis sisi paretik dan nonparetik) dinilai dengan uji normalitas menggunakan Saphiro-Wilk test untuk menguji apakah data berdistribusi normal atau tidak normal. Uji statistika untuk membandingkan karakteristik kelompok sebelum dan sesudah penelitian, digunakan uji t berpasangan jika data berdistribusi normal dan uji Wilcoxon sebagai alternatifnya jika data tidak berdistribusi normal. ${ }^{15}$

Penelitian ini telah mendapatkan persetujuan etik dari Komite Etik Penelitian Kesehatan Rumah Sakit Umum Pusat Dr. Hasan Sadikin Bandung dengan Surat Keputusan Nomor : LB.04.01/A05/EC/114IV/2017.

\section{Hasil}

Karakteristik subjek berdasarkan sisi paretik, jenis kelamin, berat badan dan usia pada penelitian ini disajikan dalam Tabel 1 berikut : 
Tabel 1 Karakteristik Subjek Penelitian

\begin{tabular}{lc}
\hline \multicolumn{1}{c}{ Variabel } & $\mathbf{N}=\mathbf{1 2}$ \\
\hline Sisi paretik & \\
Kanan & $4(33,3 \%)$ \\
Kiri & $8(66,7 \%)$ \\
Jenis kelamin & \\
Laki-laki & \\
Perempuan & $8(66,7 \%)$ \\
& $4(33,3 \%)$ \\
Beratbadan (kg) & \\
Rerata \pm SD & \\
Usia (tahun) & $64,17 \pm 14,167$ \\
Rerata \pm SD & \\
Median & \\
Kisaran & $55,50 \pm 5,072$ \\
& 58,50 \\
\hline
\end{tabular}

Perbandingan karakteristik vaskular arteri femoralis berupa perubahan diameter, PSV dan TA Max pada sisi paretic dapat dilihat pada Tabel 2 berikut :

Tabel 2 Perbandingan Karakteristik Vaskular (Diameter, PSV dan TA Max) dan Sesudah Intervensi

\begin{tabular}{|c|c|c|c|}
\hline \multirow{3}{*}{ Variabel } & \multicolumn{2}{|c|}{ Kelompok Paretik } & \multirow{3}{*}{ Nilai p } \\
\hline & Sebelum & Sesudah & \\
\hline & $\mathrm{N}=12$ & $\mathrm{~N}=12$ & \\
\hline \multicolumn{4}{|c|}{ Diameter Arteri Femoralis (mm) } \\
\hline $\operatorname{Rerata} \pm \mathrm{SD}$ & $8,51 \pm 1,409$ & $8,84 \pm 0,980$ & 0,254 \\
\hline \multicolumn{4}{|c|}{ PSV Arteri Femoralis (cm/s) } \\
\hline $\operatorname{Rerata} \pm \mathrm{SD}$ & $83,30 \pm 26,871$ & $95,31 \pm 16,008$ & 0,131 \\
\hline \multicolumn{4}{|c|}{ TA Max Arteri Femoralis (cm/s) } \\
\hline $\operatorname{Rerata} \pm \mathrm{SD}$ & $22,26 \pm 7,355$ & $25,98 \pm 5,503$ & 0,239 \\
\hline
\end{tabular}


Perubahan karakteristik vascular arteri femoralis sisi nonparetik dapat dilihat pada Tabel 3 sebagai berikut :

Tabel 3 Perbandingan Karakteristik Vaskular (Diameter, PSV dan TA Max) Arteri Femoralis pada Sisi Nonparetik Sebelum dan Sesudah Intervensi Latihan

\begin{tabular}{|c|c|c|c|}
\hline \multirow{3}{*}{ Variabel } & \multicolumn{2}{|c|}{ Kelompok Nonparetik } & \multirow{3}{*}{ Nilai p } \\
\hline & Sebelum & Sesudah & \\
\hline & $\mathbf{N}=12$ & $\mathrm{~N}=12$ & \\
\hline \multicolumn{4}{|c|}{ Diameter Arteri Femoralis (mm) } \\
\hline Rerata \pm SD & $8,76 \pm 1,099$ & $9,25 \pm 0,920$ & 0,088 \\
\hline \multicolumn{4}{|c|}{ PSV Arteri Femoralis (cm/s) } \\
\hline \multirow[t]{2}{*}{ Rerata \pm SD } & $87,27 \pm 18,15$ & $93,25 \pm 16,110$ & \\
\hline & 4 & & $\mathbf{0 , 3 0 8}$ \\
\hline \multicolumn{4}{|c|}{ TA Max Arteri Femoralis (cm/s) } \\
\hline Rerata \pm SD & $21,67 \pm 5,000$ & $25,59 \pm 5,634$ & 0,117 \\
\hline
\end{tabular}

Perbandingan besarnya perubahan diameter, PSV dan TA Max pada arteri femoralis sisi paretik dan nonparetik dapat dilihat dalam Tabel 4 berikut :

Tabel 4 Perbandingan Delta Diameter, PSV dan TA Max Arteri Femoralis pada Sisi Paretik dan Nonparetik

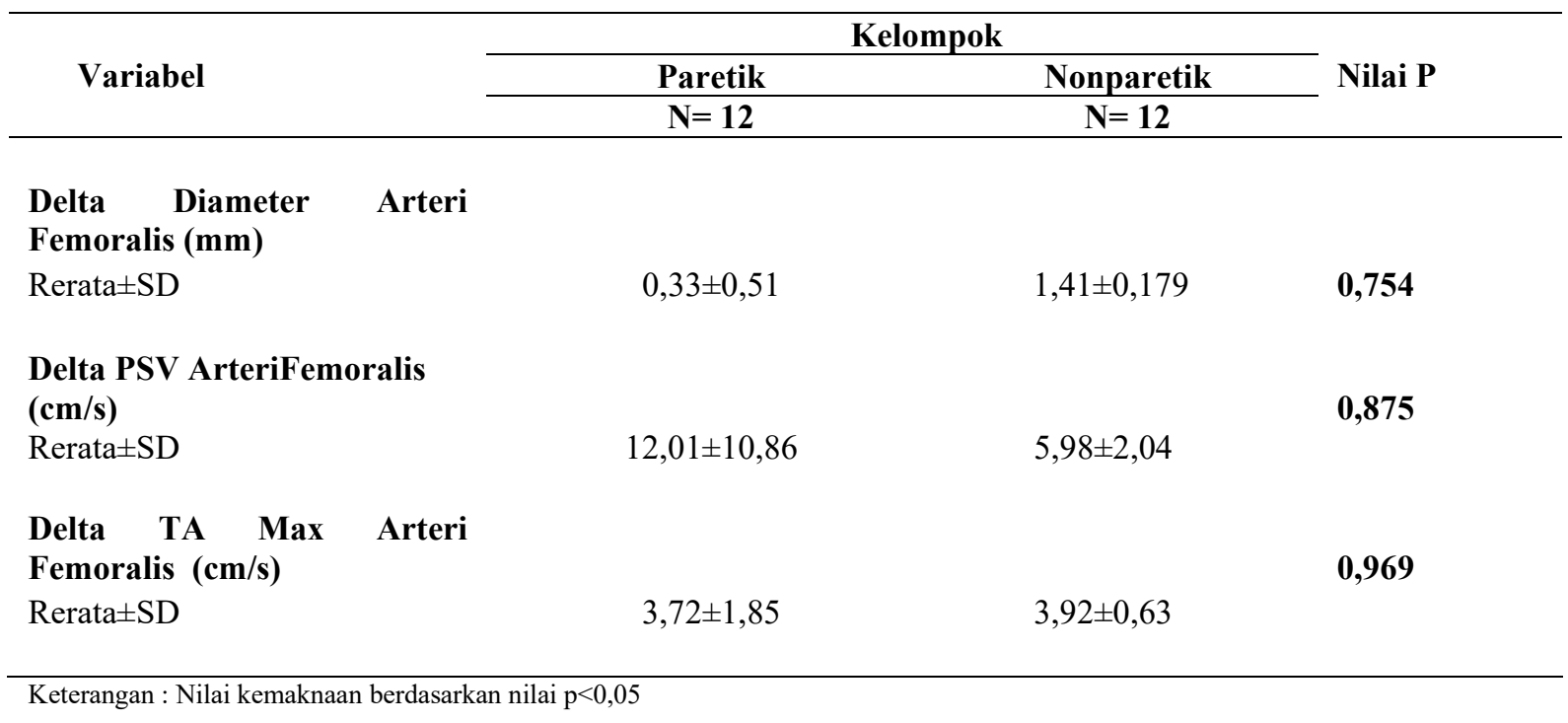


Tabel 2, 3 dan 4 menunjukkan terdapat perubahan berupa peningkatan karakteristik vaskular pada arteri femoralis baik sisi paretik maupun sisi nonparetik namun tidak berbeda secara signifikan.

\section{Diskusi}

Kecenderungan peningkatan karakteristik vascular arteri didapatkan pasca pemberian intervensi latihan. Latihan ketahanan akan memberikan efek terhadap angiogenesis dan fungsi adaptasi vascular dalam sistem sirkulasi. Peningkatan kebutuhan metabolik pada otot yang aktif berkontraksi akan meningkatkan aliran darah pada otot yang bekerja. Hal ini dibuktikan dengan adanya peningkatan PSV dan TA max yang menggambarkan kecepatan alirandarah pada arteri femoralis sisi paretik maupun sisi nonparetik.

Peningkatan kedua komponen ini akan mempengaruhi gaya gesek pulsatil pada arteri femoralis yang akan meningkatkan vasodilator sel-sel endotel pembuluh darah. Vasodilator terpenting yang mungkin terbanyak sesuai dengan studi Rodriguez, adalah nitrit oksida (NO) yang bersifat protektif dan berperan dalam mempertahankan tonus pembuluh darah. Hasil akhir dari proses ini adalah peningkatkan diameter pembuluh darah termasuk arteri femoralis. ${ }^{9,12,16}$

Hasil penelitian ini menunjukkan meskipun didapatkan peningkatan diameter, PSV dan TA Max baik pada sisi paretic maupun nonparetik, namun perbedaan peningkatannya tidak cukup signifikan secara stastistik. Hal ini dimungkinkan karena efek gaya gesek pulsatil juga dipengaruhi faktor lain selain kecepatan aliran darah. Gaya gesek pulsatil berbanding lurus dengan kecepatan aliran darah dan viskositas darah.

Penelitian ini tidak melakukan pemeriksaan viskositas darah subjek yang mungkin juga memberikan pengaruh pada perubahan diameter pembuluh darah arteri femoralis., ${ }^{71,12}$

Hal lain yang mempengaruhi perubahan karakteristik vascular adalah proses aging. Endotel pembuluh darah mengalami perubahan makroskopis dan mikroskopis seiring dengan pertambahan usia. Perubahan makroskopis yang terjadi berupa penebalan dinding pembuluh darah yang ditemukan sejak individu berusia 30 hingga 80 tahun. Perubahan mikroskopis yang terjadi meliputi perubahan structural jaringan kontraktil pada tunika intima dan media. Struktur jaringan elastin mengalami degradasi dan fragmentasi. Komposisinya digantikan oleh jaringan kolagen yang bertambah. Hal ini akan menyebabkan berkurangnya distensibilitas pembuluh darah. Proses aging juga mempengaruhi mediator kimia yang berpengaruh dalam dilatasi pembuluh darah. Studi Beyer menunjukkan pada individu dengan usia 18-55 tahun, NO sebagai vasodilator utama berada dalam kapasitas puncak. Kadar $\mathrm{NO}$ akan menurun dan $\mathrm{H}_{2} \mathrm{O}_{2}$ sebagai mediator pro inflamasi meningkat pada individu yang berusia lebih tua ( $>55$ tahun). Subjek 


\section{Research Article}


darah dan penurunan vasodilator akibat proses aging pada kisaran usia ini mungkin telah berlangsung. Seluruh perubahan menyebabkan proses adaptasi vascular berupa peningkatan diameter pembuluh arteri femoralis pasca-intervensi latihan menjadi tidak bermakna signifikan. $17,18,19$

Adaptasi vaskular yang dituju pada penelitian ini, memiliki jangka waktu yang bervariasi pada beberapa penelitian. Penelitian Billinger menunjukkan pemberian latihan ketahanan selama enam minggu pada sisi paretic pasien stroke fase kronik menunjukkan peningkatan yang signifikan terhadap diameter aliran pembuluh darah. ${ }^{6}$ Penelitian Green menunjukkan efek latihan ketahananan terhadap adaptasi vascular didapatkan setelah pemberian latihan empat hingga delapan minggu pada orang sehat. ${ }^{7}$ Penelitian ini menunjukan adanya kecenderungan peningkatan adaptasi vascular berupa peningkatan diameter, PSV dan TA Max pada arteri femoralis meskipun peningkatannya tidak signifikan secara statistik. Hal ini kemungkinan berkaitan dengan jangka waktu latihan yang diberikan selama delapan minggu belum mencapai adaptasi vaskular yang optimal. , $^{6,718}$

Penelitian ini menunjukkan kecenderungan peningkatan kecepatan aliran darah baik PSV maupun TA Max ke tungkai sisi paretic maupun nonparetik. Stroke menyebabkan penurunan aliran darah ke sisi yang paretik, seperti pada penelitian Bilinger dan kawankawan. ${ }^{5}$ Latihan ketahanan pada sisi paretic akan mengaktifkan motor unit dan otot di sisi tersebut melalui stimulasi eferen dari susunan saraf pusat. Studi Gabriel menunjukkan pada otot yang dilatih akan terjadi perbaikan firing dan pola rekrutmen otot yang tampak pada percobaan menggunakan pemeriksaaan elektromiografi. ${ }^{20}$ Peningkatan firing dan rekrutmen pada sisi paretic akan meningkatkan kebutuhan aliran darah sesuai peningkatan kebutuhan metabolik pada area tersebut. Hasil penelitian Rowell dan kawan-kawan menunjukkan peningkatan aliran darah hingga $80 \%$ ke sisi otot yang mengalami latihan. ${ }^{21}$ Hal ini sesuai dengan peningkatan aliran darah yang terjadi pada penelitian ini yang tergambar pada kecenderungan peningkatan PSV dan TA Max pada sisi paretik.

Efek sistemik terhadap sistem vascular dari latihan ketahanan sisi paretic dapat dilihat juga dari hasil peningkatan PSV dan TA Max pada arteri femoralis sisi nonparetik. Peningkatan kecepatan aliran darah baik pada arteri femoralis sisi paretic maupun sisi nonparetik akan mempengaruhi gaya gesek pulsatil pada pembuluh darah. Gaya gesek pulsatil pada pembuluh darah menginisiasit erjadinya proses remodeling pembuluh darah melalui peningkatan berbagai mediator vasodilator terutama nitrit oksida. Hasil akhir dari proses ini adalah peningkatan diameter pembuluh darah. ${ }^{13,8,11}$ 
Pemberian latihan ketahanan kuadrisep meskipun secara stastistik tidak berpengaruh secara signifikan terhadap perubahan karakteristik vaskular namun secara klinis menunjukkan kecenderungan perbaikan pada subjek penelitian. Perubahan parameter vaskular yang terjadi pasca pemberian latihan ketahanan satu tungkai baik pada sisi paretic maupun non paretic mempengaruhi adaptasi perbaikan otot pada area tersebut.

Subjek penelitian dalam evaluasi setiap dua minggunya menunjukkan perubahan berupa peningkatan repetisi maksimum untuk pemberian beban yang diberikan. 16,20,21,22

Subjek dalam penelitian ini tidak diamati mengenai aktivitas yang dilakukan seharihari di luar latihan yang diberikan. Aktivitas yang melibatkan otot besar tubuh dapat berpengaruh pada kondisi vaskularisasi subjek. Empat orang diantara subjek berjenis kelamin wanita. Pengaruh hormonal meskipun belum terlalu jelas mekanismenya dikatakan memiliki peranan terhadap kondisi vaskular. ${ }^{12,13,23}$

\section{Simpulan}

Latihan ketahanan otot kuadrisep sisi paretik tidak secara signifikan memengaruhi perubahan diameter, kecepatan puncak sistolik dan kecepatan maksimal aliran dari arteri femoralis sisi paretic maupun sisi nonparetik.

\section{Daftar Pustaka}

1. Harvey LR, Roth JE, Yu TD, Celnik P. Stroke Syndromes. Dalam: Braddom Randall. Physical Medicine and Rehabilitation. Edisi ke-4.Philadelphia:Elsevier Saunders. 2011; p 1177-8.

2. Badan Penelitian dan Pengembangan Kesehatan. Kementrian Kesehatan Republik Indonesia:Riset Kesehatan Dasar Nasional. Jakarta: Kementrian Kesehatan. 2013; h 91-4.

3. Badan Pusat Statistik Provinsi Jawa Barat. Provinsi Jawa Barat Dalam Angka.Bandung : Dinkes Provinsi Jawa Barat. 2016; h 1-11.

4. Charlene E, HaferMM. Skeletal muscle changes after hemiparetic stroke and potential effects of exercise intervention strategies. J Res Dev Serv. 2008;4(2):12-6.

5. Billinger AS, Gejewski J, Kluding M, Guo L. Single Limb Exercise Induces Femoral Artery Remodelling and Improves Blood Flow in Hemiparetic Leg After After Stroke. J Top Stroke Rehabil. 2010;17(2);1- 11.

6. Billinger AS. Cardiovascular Regulation after Stroke: evidence of impairment, trainability, and implications for rehabilitation. Cardiopulm Phys Ther J. Mar 2010;21(1):22-24.

7. Green JD, Spence A, Halliwill RJ. Cable T.Exercise and Vascular Adaptation in Symptomatic Human. J Cardiovasc. 2011;57-59.

8. Gonzales M. Shear stress effect in Vascular Respon after Sistemic Exercise. J Arch Cardiol. 2014;6:1-8.

9. Teasel R, Hussein N. Stroke Rehabilitation. Brain Reorganization, Recovery and Organized Care. J Stroke Rehabil Dis. 2010.;14:1-41.

10. Thijssen HD, Green JD. Blood Vessel Remodelling and Physical Inactivity in Human. J Appl Physiol. 2011;11(1):1836-45.

11. Pyke EK, Tschakovsky M. The Relationship Between Shear Stress and Flow Mediated dilatation: Implication For the Asessment of Endothelial Function. J Physiol. 2005; 568:357-68.

12. Silver E A, Vita A Jo. Shear Stress Mediated Arterial Remodeling in Atherosclerosis. JAHA.2016; 9:2786-9.

13. Rodriguez I, Gonzales M. Physicological Mechanism of Vascular. J Arch Cardiol. 2014;5:1-14.

14. Osada T, Saltin B, Mortensen PS, Radegran G. Measurement of The Exercising Blood Flow during Rhytmical Muscle contraction Asses by Doppler Ultra Sound. J Biomed Sci Eng. 2012 ; 779-788.

15. Sopiyudin D. Besarsampel dan carapengambilansampel. Edisi ke-3. SalembaMedik.2009; Hal 43. 


\section{Research Article}

16. Lakatta GW, Mitcel JH, Pomerance AG. Human Aging : Changes in Structure and Function.JACC; 2010; 10(2): $42-47$

17. Michael E, Selzer SC, Leonardo GC, Pamela W. Duncan and Fred H. Gage. Textbook of Neural Repair and Rehabilitation Medical Neurorehabilitation. Michael E. Selzer SC, Leonardo GC, Pamela WD and Fred HG, editor New York: Cambridge University;2006. hal. 5-47

18. Kumar S, Kumar A, Kaur J. Effect of PNF technique on gait parameters and functional mobility in hemiparetic patients. Journal of Exercise Science and Physiotherapy. 2012;8(2):67

19. Beyer A, Zinkevich N, Miller B, Liu Y, Wittenburg A, Galderi R, Gutterman D. Transition in Mechanism of Flow Mediatd Dilatation With Aging and arterial disease. J Appl Physiol. 2017; 1:112-5

20. Gabriel DA, Kamen G, Frost G. Neural adaptations to resistive exercise. Sports Med. 2006;36(2):133-49.

21. Dickstein R. Rehabilitation of gait speed after stroke: a critical review of intervention approaches. Neurorehabilitation and neural repair. 2008;22(6):649-60.

22. Staron RS, Karapondo DL, Kraemer WJ, Fry AC, Gordon SE, Falkel JE, et al. Skeletal muscle adaptations during early phase of heavy-resistance training in men and women . Journal of Applied Physiology. 2004;76 (3): 124755 .

23. William J. Kraemer SJ. Exercise Physiology Integrating Theory and Application. Edisi ke-1. Philadelphia: Lippincott Williams \& Wilkins;2012. hal. 69-131. 